\title{
Complications and outcome after free flap surgery for cancer of the head and neck
}

Sanna Lahtinen ${ }^{{ }^{*}}$, Petri Koivunen ${ }^{b, 1}$, Tero Ala-Kokko ${ }^{a, 1}$, Outi Kaarela ${ }^{c}$, Pasi Ohtonen ${ }^{d}$, Päivi Laurila d, Janne H Liisanantti ${ }^{\text {a }}$

a University of Oulu, Medical Research Center, Research Group of Surgery, Anaesthesia and Intensive Care and Department of Anaesthesiology, Oulu University Hospital, Finland.

${ }^{\mathrm{b}}$ University of Oulu, Medical Research Center, PEDEGO Research Unit, Department of Otorhinolaryngology and Head and Neck, Oulu University Hospital, Finland

' University of Oulu, Medical Research Center, Research Group of Surgery, Anaesthesia and Intensive Care and Department of Surgery, Oulu University Hospital, Finland

${ }^{d}$ University of Oulu, Division of Operative care and Medical Research Center, Oulu University Hospital, Finland

${ }^{1}$ These authors have contributed equally to the work

*corresponding author

Address: Department of Anaesthesia and Intensive Care, Oulu University Hospital, P.O. Box 21, FI90029 Oulu, Finland. E-mail address: sanna.lahtinen@ppshp.fi

\section{Abstract}

This study evaluated the complications following free flap surgery for cancer of the head and neck, assessed factors associated with the complications, and analyzed the impact of the complications on outcome.

This retrospective single-center study included 136 patients who underwent free flap surgery for cancer of the head and neck between 2008 and 2015. Preoperative and perioperative data and surgical and medical complications were recorded. The impact of the complications on hospital length of stay (LOS) and survival were assessed. 
A total of $86 / 136(63.2 \%)$ patients had complications. Compared to patients without complications, these patients had a higher rate of alcohol abuse ( $24.4 \%$ vs. $10.0 \%, p=0.039)$, longer operation time (565 [458-653] vs. 479 [418-556] $\mathrm{min}, \mathrm{p}<0.001)$ and higher intraoperative blood loss (725 [400-1150] vs. 525 [300-800] mL, p=0.042). Fibular flap surgery and stage T4 were more frequent in patients with complications ( $26 \%$ vs. $8 \%, p=0.010 ; 55 \%$ vs. $34 \%, p=0.015$, respectively). Patients with complications had longer hospital LOS (9 [7-12] vs. 15 [10-21] days, $p<0.001)$ than those without complications. The cumulative mortality was higher for patients with late (occurred after the fourth postoperative day) complications (61.4\% vs. $35.5 \%, p=0.004)$. In conclusion, more than half of the patients had complications that were related to alcohol abuse, a more complicated intraoperative course and fibular flap surgery. The complications were related to longer hospital LOS, and patients with late complications had higher mortality than those without.

\section{Introduction}

Postoperative complications frequently occur after major head and neck surgery with free flap repair, with the reported complication rate ranging between $34 \%$ and $85 \%{ }^{1-5}$ Several variables are associated with an increased risk for postoperative complications in this patient group, including smoking, advanced age, ASA class (American Society of Anesthesiologists risk classification) and excessive fluid management..$^{2,6-7}$ However, previous studies have not reported complications in detail, and there are different ways to classify complications, making it difficult to compare different studies. Moreover, the impact of postoperative complications on recovery, hospital length of stay (LOS), oncological treatment plan and outcome remains unclear. ${ }^{1,5,8-10}$ Because the 
rate of postoperative complications in this patient group is relatively high, patient selection, prognosis and the true cost of microvascular surgery continue to be discussed. ${ }^{1,7}$

Accordingly, we aimed to evaluate the onset and distribution of surgical complications and their impact on postoperative recovery and outcome in a cohort of patients who underwent major head and neck surgery with free flap repair. Specifically, we aimed to evaluate pre- and perioperative factors related to complications and their impact on hospital LOS and survival.

\section{Materials and methods}

Setting

This retrospective registry study was conducted at Oulu University Hospital, which is a university hospital that provides tertiary-level care for 750000 inhabitants in Northern Finland. All of the analyzed data was collected for clinical or administrative purposes. The study was approved by the hospital administration and by the local ethics committee (The Regional Ethics Committee of the Northern Ostrobothnia Hospital, 95/2016).

Patients and inclusion criteria

All of the patients who underwent surgery due to cancer of the head and neck with free flap repair in 2008-2015 at Oulu University Hospital were screened for inclusion in the study by reviewing the operation records of the head and neck surgery unit. During study period, a total of 156 free flap operations were performed. Of these, 3 involved non-malignant tumors, 12 were reoperations due to flap failures, 2 patients were operated due to traumatic injury and 3 cases had inadequate data; thus, 136 patients were included in the study. 
The data were collected from the medical records, anesthesia charts, laboratory results, radiological statements and ICU (intensive care unit) database (Centricity Critical Care Clinisoft, GE Healthcare). The data included tumor data; patient demographic information, including intraoperative variables; postoperative ICU data; and postoperative surgical ward data recorded during the hospital stay. The hospital LOS was calculated as the time from the day of surgery until discharge. The data were collected using structured forms and then digitalized. The Population Register Centre of Finland provided data concerning the dates of deaths of the non-survivors. Survival was followed until April 30, 2017.

\section{Complications}

The postoperative complications that were recorded by the treating physicians were extracted from the medical records. The analysis included all postoperative complications during the hospital stay, both surgical and medical, as well as those that occurred within the 30 days after hospital discharge.

Surgical complications included surgical site infection, surgical site hematoma, the need for reoperation, partial flap failure and total flap failure. Medical complications included pneumonia, myocardial infarction, sepsis, acute kidney injury (AKI), stroke, pulmonary embolism, deep venous thrombosis and pulmonary edema. Complication onset was determined with an accuracy of one day. Complications were categorized as early complications i.e. onset 1-4 days postoperatively or as late complications i.e. onset more than 4 days postoperatively.

\section{Statistical analysis}

The data were analyzed using SPSS for Windows (IBM Corp., 2013; IBM SPSS Statistics for Windows, Version 22.0. Armonk, NY, USA). Categorical variables are presented as absolute 
numbers ( $\mathrm{n}$ ) and percentages (\%) and were compared using the Pearson chi-square test.

Continuous variables are presented as medians with $25^{\text {th }}$ and $75^{\text {th }}$ percentiles $\left[25^{\text {th }}-75^{\text {th }} \mathrm{PCT}\right]$ and were analyzed using the non-parametric Mann-Whitney test. Kaplan-Meier survival curves were drawn to analyze the long-term mortality. A p-value less than 0.05 was considered statistically significant.

\section{Results}

A median of 16 (range 8-29) operations were performed annually from 2008 to 2015 . The median age of the study population was 65 years, and 75 (55\%) were male. The majority of patients were recorded as ASA class 3-4 $(54 \%, n=73)$ and received postoperative treatment in the ICU (98\%, n=133). (Table 1). The median follow-up time was 26 [14-51] months.

\section{Complications}

A total of 86 (63.2\%) of the 136 patients had at least one postoperative complication. The percentage of patients with medical complications was $37.5 \%(n=51)$, and the percentage of patients with surgical complications was $47.1 \%(n=64) ; 21.3 \%(n=29)$ of the patients had both medical and surgical complications.

The most common medical complication was pneumonia (51\%) and the most common surgical complication was surgical site infection (49\%) (Table 2). Compared to patients without complications, patients with complications had a higher rate of alcohol abuse $(24.4 \%$ vs. $10.0 \%$, $p=0.039)$, longer operation time (565 [458-653] vs. 479 [418-556] $\mathrm{min}, \mathrm{p}<0.001)$ and higher intraoperative blood loss (725 [400-1150] vs. 525 [300-800] mL, $p=0.042$ ). Patients with complications more frequently had fibular free flaps ( $26 \%$ vs. $8 \%, p=0.010)$ and stage T4 tumors 
( $59 \%$ vs. $34 \%, p=0.015$ ) compared to those without complications. There was no difference in the preoperative risk classification according to ASA or comorbidities (Table 1).

The procedures requiring fibula free flap were more often performed in patients with stage T4 tumor ( 24 of 26 vs 40 of 101, $\mathrm{P}<0.001$. They also had higher intraoperative blood loss (1050 [560$1300] \mathrm{ml}$ vs 520 [350-900]ml, $\mathrm{P}<0.001$ ) and longer duration of operation (632 [575-715] min vs 493 [425-574] $\min , \mathrm{P}<0.001)$.

Early complications were recorded in 69 patients (50.7\%). Those with early complications had a higher rate of any late complication (44 [63.8\%] vs. 14 [20.9\%], $p<0.001$ ). Patients with early complications had a higher rate of alcohol abuse ( $26.1 \%$ vs. $11.9 \%, p=0.036)$, longer operation time (566 [451-660] vs. 495 [423-569] $\mathrm{min}, \mathrm{p}=0.016)$, longer hospital LOS (15 [10-22] vs. 10 [814] days, $p<0.001)$ and more often had stage T4 tumors $(64.0 \%$ vs. $35 \%, p=0.004)$ compared to patients without early complications (Table 3).

Of the medical complications, myocardial infarction was the earliest (3 [1-8] postoperative days), while surgical site exploration (1 [0-2] postoperative days) and hematoma evacuation (2 [16] postoperative days) were the earliest surgical procedures that were performed because of complications. The median time for infectious complications (i.e. surgical site infection, sepsis or pneumonia) was 5 (3-9) days after the operation (Table 2). A total of 18 patients had a reoperation within 7 days and 5 of these had later a flap failure (data not shown).

\section{Outcome}

Patients with complications had longer ICU LOS (24.0 [19.2-43.2] vs. 21.6 [19.2-24.0] hours, $p=0.022)$ and longer hospital LOS $(15[10-21]$ vs. 9 [7-12] days, $p<0.001)$ (Table 1). A total 45 (52.9\%) of the patients with complications died by April 30, 2017, in contrast to 17 (35.4\%, $p=0.072$ ) patients without complications (data not shown). Medical complications and ICU 
readmissions, as well as $\mathrm{N}$-stage 3 , were more frequent in those who died within one year (Table 4).

Patients with late complications had higher mortality than patients without late complications (Fig. 1), but there was no difference in mortality between those with versus without early complications (data not shown).

\section{Discussion}

To our knowledge, this is the first study focusing on the impact and onset of complications on patient postoperative course and outcome in patients who underwent free flap surgery for cancer of the head and neck. The main finding of the present study was that more than half of the patients had postoperative complications. Patients with complications had a higher rate of alcohol abuse, hypoalbuminemia and T4 tumors, a more complicated intraoperative course and more frequently underwent fibular free flap reconstruction. Late complications were associated with poor long-term outcome and with significantly worse survival which were often the result of early complications.

The complication rate in our study, $63.2 \%$, was higher than that in some previous studies, which reported complication rates between $40 \%$ and $53 \%$. This might be explained by differences in how the complications were recorded..$^{2,8,9,11}$ We did not categorize the complications as severe versus non-severe. Instead, we were interested in the timing of complication onset and aimed to record each complication that might possibly affect patient postoperative course and recovery. Moreover, there is a lack of standardization in the classification of postoperative complications after free flap surgery for cancer of the head and neck. The classification and the definitions of complications varies in previous studies (major vs. minor; surgical vs. medical; mild vs. moderate vs. severe); this makes it difficult to compare outcomes and risk factors for possible poor 
outcomes. There is also continued debate about the use of grading systems that are commonly used for postoperative complications in other fields of surgery. ${ }^{1,2,5,8,9}$ In the present study, we used a simple classification for medical and surgical complications that could be reliably used in our retrospective review of medical records. The present study was performed in a low volume center, with median annual operation rate of 16 . In the previous studies the annual operation rate has varied between $14-38 \cdot 3,7,8$ However, the annual complication rate cannot be explained by this due to heterogeneity of the classification of the complications. Also Klosterman et al did not find differences in complication rates between low-volume and high-volume centers. ${ }^{3}$

Previous studies have found that smoking, comorbidity and advanced age are potential risk factors for postoperative complications after free flap surgery for cancer of the head and neck .2,6,7 In our study, we did not find a significant correlation between these factors and complications. The high proportion of smokers (41\%) in our population may explain the difficulty to show the possible impact of smoking on complications. The majority of the patients in this study were recorded as ASA 3-4, but we did not find that this had a significant effect on postoperative complications $(p=0.084)$. However, the fibular free flap method was associated with complications $(p=0.010)$. Further, previous studies found that free flaps with bone or composite flaps are associated with postoperative complications. ${ }^{1,18}$ Microvascular surgery with bone flap is a technically more demanding procedure compared to surgery with soft tissue flaps. According to our results, the duration of the operation is longer and blood loss during resection is usually higher. This is in line with the results of Mücke et al. ${ }^{18}$ Moreover, in the present study, fibula free flap was more frequent in patients with extensive disease. All these influence postoperative complications and outcome. The surgical insult of major procedures evokes an inflammatory response in patients and contributes to the development of postoperative infectious complications. ${ }^{12}$ 
In the present study, $97.8 \%$ of the patients were admitted to the ICU for immediate postoperative care. The median ICU LOS was less than 24 hours, and most of the complications were recorded after ICU discharge. There is no consensus regarding the need for postoperative management in the ICU after free flap surgery of the head and neck. In major abdominal surgery, it is essential to accurately assess the need for postoperative ICU management to ensure highquality patient care, since this could improve outcomes. ${ }^{13}$ Although the high cost of routine postoperative ICU care is a concern ${ }^{14,15}$, the present results still suggest that in certain cases (alcohol abuse, use of a free flap with bone, high intraoperative blood loss), planning for a longer ICU stay and better monitoring after ICU discharge could help prevent early medical complications.

In our study, complications prolonged the median hospital LOS 6 days. Alcohol abuse and pulmonary problems can lead to postoperative medical complications, which are known to be an important factor in increasing the true costs after microsurgical reconstruction for cancer of the head and neck. ${ }^{7}$ Early mobilization and respiratory physiotherapy intervention may be essential for reducing the high rate of postoperative pneumonia after free flap surgery.

The reported impact of postoperative complications on survival and mortality after free flap surgery for cancer of the head and neck has varied in previous studies. ${ }^{5,16,17}$ Unlike the present study, the recent prospective trial by McMahon et al. did not analyze the onset of complications on outcome. ${ }^{17}$ Here we reported the significant effect of late complications on mortality, which has not been analyzed before. Medical complications, more advanced cancer $(\mathrm{N}$-score $>2)$ and readmission to ICU were all associated with worsened one-year survival. Patients with complications had also significantly higher five-year mortality compared to patients without complications. Our results showed that all postoperative complications had a negative effect on outcome and survival after free flap surgery for cancer of the head and neck. 


\section{Limitations}

This study had some limitations due its retrospective design and the relatively small number of patients. Alcohol abuse was more frequently found in patients with complications. Due to retrospective design we were not able to use validated methods, such as AUDIT to determine the alcohol consumption habits of the study population and alcohol abuse was retrieved from the patients' medical history. This should be noted when interpreting the results. Nevertheless, this study population represents an unselected cohort of patients with head and neck cancer who underwent resection of a malignant tumor using free flap surgery. In this study setting, we were only able to show an association of early complications with late complications, which significantly increased hospital LOS and worsened survival. Showing a robust causal effect would require a prospective study and adjustment of perioperative factors. However, we found a higher rate of late complications in patients with early complications. We were not able to analyze the medical complications as risk factors for surgical complications or vice versa due to the limited number of patients. The role of early complications should be studied in a large, prospective multicenter study to identify the origin of the complications and to determine whether they are patient- or procedure-related.

\section{Clinical impact}

The present results suggest that there should be a greater focus on preventing early complications. Careful attention should be payed to the preoperative and immediate postoperative optimization of patients who are undergoing this operation, and the most suitable surgical technique should be carefully considered. Moreover, instead of focusing on health-related risk factors such as ASA classification or chronic conditions, our results suggest that certain at-risk 
populations, like those who abuse alcohol or those who are malnourished, should be identified when planning the surgery and the postoperative care. If possible, the use of less invasive reconstruction techniques and free flaps without bone should be evaluated for patients who are at high risk for postoperative complications. The present results also suggest that in the future studies the classification of the complications should include the onset of complications since it has an impact on the long-term outcome. Also, according to our results, the focus should be on tumor staging, different surgical techniques and perioperative course instead of health related risk-factors when designing studies of postoperative complications following free flap surgery of the cancer of head and neck.

\section{Conclusion}

More than half of the patients who underwent microvascular free flap reconstruction had complications that were related to alcohol abuse, a more complicated intraoperative course and reconstruction with composite free flap with bone. Most of the complications were recorded after ICU discharge, and infectious complications occurred after postoperative day 5 . The complications increased hospital LOS, and late complications had a significant effect on mortality.

Legend for figure:

Figure 1. Kaplan-Meier survival curves for the 136 patients who underwent free flap surgery for cancer of the head and neck who had late complications and who had no late complications 
Conflict of interest: none.

This research did not receive any specific grant from funding agencies in the public, commercial, or not-for-profit sectors.

\section{References}

1. McMahon JD, Maclver C, Smith M, et al. Postoperative complications after major head and neck surgery with free flap repair--prevalence, patterns, and determinants: A prospective cohort study. Br J Oral Maxillofac Surg 2013;51(8):689-95.

2. Clark JR, McCluskey SA, Hall F, et al. Predictors of morbidity following free flap reconstruction for cancer of the head and neck. Head Neck 2007;29(12):1090-101.

3. Klosterman T, Siu E, Tatum S. Free flap reconstruction experience and outcomes at a lowvolume institution over 20 years. Otolaryngology - Head \& Neck Surgery 2015;152(5):832-7.

4. Lahtinen SL, Liisanantti JH, Poukkanen MM, et al. Goal-directed fluid management in free flap surgery for cancer of the head and neck. Minerva Anestesiol 2017;83(1):59-68.

5. Perisanidis C, Herberger B, Papadogeorgakis N, et al. Complications after free flap surgery: Do we need a standardized classification of surgical complications? Br J Oral Maxillofac Surg 2012;50(2):113-8.

6. Patel RS, McCluskey SA, Goldstein DP, et al. Clinicopathologic and therapeutic risk factors for perioperative complications and prolonged hospital stay in free flap reconstruction of the head and neck. Head Neck 2010;32(10):1345-53. 
7. Jones NF, Jarrahy R, Song Jl, et al. Postoperative medical complications--not microsurgical complications--negatively influence the morbidity, mortality, and true costs after microsurgical reconstruction for head and neck cancer. Plastic \& Reconstructive Surgery 2007;119(7):2053-60.

8. Lodders JN, Parmar S, Stienen NLM, et al. Incidence and types of complications after ablative oral cancer surgery with primary microvascular free flap reconstruction. Medicina Oral, Patologia Oral y Cirugia Bucal 2015;20(6):744-50.

9. Broome M, Juilland N, Litzistorf $\mathrm{Y}$, et al. Factors influencing the incidence of severe complications in head and neck free flap reconstructions. Plastic and Reconstructive Surgery Global Open 2016;4(10):e1013.

10. Farwell DG, Reilly DF, Weymuller EAJ, et al. Predictors of perioperative complications in head and neck patients. Archives of Otolaryngology -- Head \& Neck Surgery 2002;128(5):505-11.

11. Bianchi B, Copelli C, Ferrari S, et al. Free flaps: Outcomes and complications in head and neck reconstructions. Journal of Cranio-Maxillo-Facial Surgery 2009;37(8):438-42.

12. Watt DG, Horgan PG, McMillan DC. Routine clinical markers of the magnitude of the systemic inflammatory response after elective operation: A systematic review. Surgery 2015;157(2):362-80.

13. Sobol JB, Wunsch H. Triage of high-risk surgical patients for intensive care. Crit Care 2011;15(2):217.

14. Panwar A, Smith R, Lydiatt D, et al. Vascularized tissue transfer in head and neck surgery: Is intensive care unit-based management necessary?. Laryngoscope 2016;126(1):73-9. 
15. Arshad H, Ozer HG, Thatcher A, et al. Intensive care unit versus non-intensive care unit postoperative management of head and neck free flaps: Comparative effectiveness and cost comparisons. Head Neck 2014;36(4):536-9.

16. Ch'ng S, Choi V, Elliott M, et al. Relationship between postoperative complications and survival after free flap reconstruction for oral cavity squamous cell carcinoma. Head Neck 2014;36(1):55-9.

17. McMahon J, Handley TBP, Bobinskas A, et al. Postoperative complications after head and neck operations that require free tissue transfer- prevalence, morbidity and cost. Br J Oral Maxillofac Surg 2017.doi:10.1016/j.bjoms.2017.07.015.

18. Mücke T, Loeffelbein DJ, Kolk A, et al. Comparison of outcome of microvascular bony head and neck reconstructions using the fibular free flap and the iliac crest flap. Br J Oral Maxillofac Surg 2013;51:514-9. 
Table 1: Perioperative characteristics and postoperative outcome of 136 patients who underwent free flap surgery for cancer of the head and neck.

\begin{tabular}{|c|c|c|c|c|}
\hline Characteristic & $\begin{array}{l}\text { All patients } \\
\mathrm{n}=136\end{array}$ & $\begin{array}{l}\text { Patients with no } \\
\text { complications } \\
n=50\end{array}$ & \begin{tabular}{|l|} 
Patients with \\
complications \\
$\mathrm{n}=86$ \\
\end{tabular} & p-value \\
\hline Gender, $\mathrm{m} / \mathrm{f}$ & 75/61 (55.1/44.9) & $23(46.0) / 27(54.0)$ & $52(60.5) / 34(39.5)$ & 0.10 \\
\hline Age, years & $65[59-74]$ & $65[57-71]$ & $66[59-74]$ & 0.43 \\
\hline ASA classification, 3-4 & $73(53.7)$ & $22(44.0)$ & $51(59.3)$ & 0.084 \\
\hline $\mathrm{BMI}$ & $23.3[20.2-26.2]$ & $22.6[20.5-26.5]$ & $23.6[19.7-26.0]$ & 0.83 \\
\hline Smoking & 56 (41.2) & $21(42.0)$ & 35 (40.7) & 0.88 \\
\hline Alcohol abuse & 26 (19.1) & $5(10.0)$ & 21 (24.4) & 0.039 \\
\hline Comorbidity & 95 (69.9) & $32(64.0)$ & $63(73.3)$ & 0.26 \\
\hline \multicolumn{5}{|l|}{ Charlson Comorbidity Index } \\
\hline $\mathrm{CCl}>0$ & 54 (39.7) & $19(38.0)$ & 35 (40.7) & 0.76 \\
\hline Medication & 85 (62.5) & $30(60.0)$ & $55(64.0)$ & 0.65 \\
\hline \multicolumn{5}{|l|}{$\begin{array}{l}\text { Preoperative laboratory } \\
\text { results }\end{array}$} \\
\hline Hemoglobin, $\mathrm{g} / \mathrm{L}$ & 132 [121-143] & 134 [127-145] & 131 [118-141] & 0.15 \\
\hline Creatinine, $\mu \mathrm{mol} / \mathrm{L}$ & $63[55-72]$ & $61[54-69]$ & $65[55-73]$ & \\
\hline \multicolumn{4}{|l|}{$\begin{array}{l}\text { Hypoalbuminemia }(\mathrm{alb}<36) \\
\text { Tumor site }\end{array}$} & 0.38 \\
\hline Oral cavity/tongue & 57 (41.9) & $24(48.0)$ & 33 (38.4) & \multirow{8}{*}{0.51} \\
\hline Maxilla & $12(8.8)$ & $3(6.0)$ & $9(10.5)$ & \\
\hline Mandibula & $23(16.9)$ & $7(14.0)$ & $16(18.6)$ & \\
\hline Larynx/pharynx & $12(8.8)$ & $3(6.0)$ & $9(10.5)$ & \\
\hline Cutaneous & $10(7.4)$ & $4(8.0)$ & $6(7.0)$ & \\
\hline Palatinal & $10(7.4)$ & $6(12.0)$ & $4(4.7)$ & \\
\hline Buccal mucosa & $8(5.9)$ & $3(6.0)$ & $5(5.8)$ & \\
\hline Other & $4(2.9)$ & $0(0.0)$ & $4(4.7)$ & \\
\hline \multirow{2}{*}{$\begin{array}{l}\text { Tumor staging } \\
\text { T-score T1 }\end{array}$} & $n=127$ & $n=47$ & $n=80$ & \multirow{5}{*}{0.015} \\
\hline & $5(3.9)$ & $2(4.2)$ & $3(3.8)$ & \\
\hline $\mathrm{T} 2$ & $31(24.4)$ & $12(25.5)$ & $19(23.8)$ & \\
\hline T3 & $28(22.0)$ & $17(36.2)$ & $11(13.8)$ & \\
\hline T4 & $63(49.6)$ & $16(34.0))$ & $47(58.8)$ & \\
\hline $\mathrm{N}$-score NO & $80(63.0)$ & $35(74.5)$ & $45(56.3)$ & \\
\hline N1 & $19(15.0)$ & $6(12.8)$ & $13(16.3)$ & \\
\hline N2 & $26(20.5)$ & $5(10.6)$ & $21(26.3)$ & 0.14 \\
\hline N3 & $2(1.6)$ & $1(2.1)$ & $1(1.3)$ & \\
\hline Preoperative radiotherapy & & & & \\
\hline No need & 96 (70.6) & $35(70.0)$ & 61 (70.9) & \\
\hline
\end{tabular}




\begin{tabular}{|c|c|c|c|c|}
\hline 0-3 months before operation & $2(1.5)$ & $0(0.0)$ & $2(2.3)$ & \multirow[t]{3}{*}{0.69} \\
\hline 3-12 m before operation & $9(6.6)$ & $3(6.0)$ & $6(7.0)$ & \\
\hline$>12 \mathrm{~m}$ before operation & $29(21.3)$ & $12(24.0)$ & $17(19.8)$ & \\
\hline \multicolumn{5}{|l|}{ Free flap } \\
\hline RFA & $42(30.9)$ & $22(44.0)$ & $20(23.3)$ & 0.011 \\
\hline ALT & $39(28.7)$ & $15(30.0)$ & $24(27.9)$ & 0.80 \\
\hline LD & $3(2.2)$ & $0(0.0)$ & $3(3.5)$ & - \\
\hline Scapula & $7(5.1)$ & $2(4.0)$ & $5(5.8)$ & 0.64 \\
\hline Fibula & $26(19.1)$ & $4(8.0)$ & $22(25.6)$ & 0.010 \\
\hline Lateral arm & $9(6.6)$ & $4(8.0)$ & $5(5.8)$ & 0.62 \\
\hline Other & $10(7.4)$ & $3(6.0)$ & $7(8.1)$ & 0.65 \\
\hline Tracheostomy & $111(81.6)$ & $40(80.0)$ & $71(82.6)$ & 0.44 \\
\hline Neck dissection bilateral & $28(20.6)$ & $8(16.0)$ & $20(23.3)$ & 0.51 \\
\hline Time in operation room, min & 613 [540-707] & $561[500-614]$ & $647[561-733]$ & $<0.001$ \\
\hline Duration of operation, $\min$ & 527 [437-625] & $479[418-556]$ & 565 [458-653] & 0.001 \\
\hline Total fluids received, $\mathrm{mL}$ & $6460[5400-8420]$ & 6310 [4600-8200] & 6940 [5400-8820] & 0.096 \\
\hline Red blood cells received, $\mathrm{mL}$ & $260[0-520]$ & $0[0-520]$ & $260[0-520]$ & 0.025 \\
\hline Blood loss, $\mathrm{mL}$ & $600[385-1000]$ & $525[300-800]$ & 725 [400-1150] & 0.042 \\
\hline Antibiotic treatment $>48 \mathrm{~h}$ & $105(77.2)$ & $28(56.0)$ & 77 (89.5) & $<0.001$ \\
\hline $\begin{array}{l}\text { Postoperative ventilator } \\
\text { support, } \mathrm{h}\end{array}$ & $13.7[9.6-17.0]$ & $12[7.2-14.4]$ & $14.4[9.6-19.2]$ & 0.009 \\
\hline Postoperative sedation, $\mathrm{h}$ & $11.5[5.5-15.8]$ & $9.6[4.8-14.4]$ & $12.0[7.2-16.8]$ & 0.065 \\
\hline Hos LOS, days & $13[9-17]$ & $9[7-12]$ & $15[10-21]$ & $<0.001$ \\
\hline ICU LOS, hours & $21.6[19.2-41.3]$ & $21.6[19.2-21.6]$ & $24.0[19.2-43.2]$ & 0.022 \\
\hline Discharge disposition home & $82(60.3)$ & $37(74.0)$ & $45(52.3)$ & 0.003 \\
\hline \multicolumn{4}{|l|}{ Oncologic treatment } & \multirow{4}{*}{0.49} \\
\hline No need & $39(28.7)$ & $5(10.0)$ & $34(38.4)$ & \\
\hline Curative treatment & $69(50.7)$ & $27(54.0)$ & $42(50.0)$ & \\
\hline Palliative treatment & $18(13.2)$ & $8(16.0)$ & $10(11.6)$ & \\
\hline $\begin{array}{l}\text { Onset of assessment for } \\
\text { oncologic treatment, days }\end{array}$ & 44 [29-75] & $44[35-67]$ & $44[28-72]$ & 0.97 \\
\hline Discharge disposition home & $82(60.3)$ & $37(74.0)$ & $45(52.3)$ & 0.070 \\
\hline 30-day mortality & $1(0.7)$ & $0(0.0)$ & $1(1.2)$ & 0.44 \\
\hline 90-day mortality & $3(2.2)$ & $0(0.0)$ & $3(3.5)$ & 0.18 \\
\hline 180-day mortality & $8(5.9)$ & $1(2.0)$ & $7(8.1)$ & 0.14 \\
\hline 1-year mortality & 27 (19.9) & $9(18.0)$ & $18(20.9)$ & 0.68 \\
\hline 2-year mortality & $48 / 121$ (39.7) & $14 / 46(30.4)$ & $34 / 75(45.3)$ & 0.10 \\
\hline 5-year mortality & 60/87 (69.0) & $16 / 29(55.2)$ & $44 / 58$ (75.9) & 0.049 \\
\hline
\end{tabular}


ASA: American Society of Anaesthesiologists; BMI: body mass index; RFA: radial forearm; ALT: anterolateral thigh; LD: latissimus dorsi; Hosp LOS: hospital length of stay; ICU LOS: intensive care length of stay

\begin{tabular}{|l|l|l|}
\hline Complications & Frequency, \% & $\begin{array}{l}\text { Onset of } \\
\text { complications, days }\end{array}$ \\
\hline Medical complications & 70 & $7[3-9)$ \\
\hline Pneumonia & $36(51.4)$ & $5[3-7]$ \\
\hline Sepsis & $9(12.9)$ & $8[7.5-11.5]$ \\
\hline Myocardial infarction & $7(10.0)$ & $3[1-8]$ \\
\hline Pulmonary edema & $13(18.6)$ & $7[5-9]$ \\
\hline Pulmonary embolism & $1(1.4)$ & 13 \\
\hline Deep venous thrombosis & $2(2.9)$ & $9 \& 11$ \\
\hline Stroke & $1(1.4)$ & 2 \\
\hline Acute kidney injury & $1(1.4)$ & 23 \\
\hline Surgical complications & 73 & $5[2-10]$ \\
\hline Surgical site infection & $36(49.3)$ & $6[3-11]$ \\
\hline Surgical site hematoma & $22(30.1)$ & $6[1-9]$ \\
\hline Partial flap failure & $5(6.8)$ & $10[3-14]$ \\
\hline Total flap failure & $10(13.7)$ & \\
\hline Need for reoperation & 72 & $9[1-15]$ \\
\hline Surgical site revision & $20(27.8)$ & $14[9-18]$ \\
\hline Surgical site exploration & $18(25.0)$ & $1[0-2]$ \\
\hline Evacuation of hematoma & $17(23.6)$ & $2[1-6]$ \\
\hline New free flap & $10(13.9)$ & $14[9-22]$ \\
\hline New other flap & $7(9.7)$ & $14[8-21]$ \\
\hline ICU readmission & 8 & $7[4-17]$ \\
\hline
\end{tabular}

\section{Table 2}

The 143 complications and their onset in 136 patients who underwent free flap surgery for cancer of the head and neck 
Table 3

Differences between patients who underwent free flap surgery for cancer of the head and neck who did or did not have early onset complications

\begin{tabular}{|c|c|c|c|}
\hline Variable & $\begin{array}{l}\text { Early complications } \\
n=69\end{array}$ & $\begin{array}{l}\text { No early } \\
\text { complications } \\
n=67\end{array}$ & p-value \\
\hline ASA classification 3-4 & $36(52.2)$ & $37(55.2)$ & 0.72 \\
\hline APACHEII & $13[10-15]$ & $12[11-15]$ & $>0.9$ \\
\hline SOFA admission & $3[2-4]$ & $3[2-4]$ & 0.40 \\
\hline $\begin{array}{l}\text { Charlson Comorbidity } \\
\text { Index }>0\end{array}$ & $26(37.7)$ & $28(41.8)$ & 0.62 \\
\hline Smoking & $28(40.6)$ & $28(41.8)$ & 0.89 \\
\hline $\begin{array}{l}\text { Tumor staging } \\
\text { T-score T1 }\end{array}$ & 2 & 17 & \multirow{4}{*}{0.004} \\
\hline $\mathrm{T} 2$ & 14 & 17 & \\
\hline T3 & 7 & 21 & \\
\hline $\mathrm{T} 4$ & 41 & 22 & \\
\hline $\mathrm{N}$-score NO & 36 & 44 & \multirow{4}{*}{0.45} \\
\hline N1 & 11 & 8 & \\
\hline $\mathrm{N} 2$ & 16 & 10 & \\
\hline N3 & 1 & 1 & \\
\hline Alcohol abuse & $18(26.1)$ & $8(11.9)$ & 0.036 \\
\hline \multirow{2}{*}{$\begin{array}{l}\text { Preoperative radiotherapy } \\
\text { No need }\end{array}$} & & & \\
\hline & $49(71.0)$ & $47(70.1)$ & \multirow{4}{*}{0.49} \\
\hline $\begin{array}{l}0-3 \text { months before } \\
\text { operation }\end{array}$ & $2(2.9)$ & $0(0)$ & \\
\hline $\begin{array}{l}\text { 3-12 months before } \\
\text { operation }\end{array}$ & $5(7.2)$ & $4(6.0)$ & \\
\hline $\begin{array}{l}>12 \text { months before } \\
\text { operation }\end{array}$ & $13(18.9)$ & $16(23.9)$ & \\
\hline Free flap with bone & $21(30.4)$ & $12(17.9)$ & 0.088 \\
\hline Perioperative blood loss & 750 [400-1150] & $530[350-898]$ & 0.079 \\
\hline Length of operation & 566 [451-660] & $495[423-569]$ & 0.016 \\
\hline Postoperative ventilator time & $0.60[0.43-0.76]$ & $0.54[0.30-0.67]$ & 0.037 \\
\hline Hosp LOS, days & $15[10-22]$ & $10[8-14]$ & $<0.001$ \\
\hline ICU LOS, hours & $1.1[0.8-1.8]$ & $0.9[0.8-1.6]$ & 0.089 \\
\hline Any late complication & $44(63.8)$ & $14(20.9)$ & $<0.001$ \\
\hline Late surgical site infection & $22(31.9)$ & $0(0.0)$ & $<0.001$ \\
\hline Late surgical site hematoma & $12(17.4)$ & $1(1.5)$ & 0.002 \\
\hline Late partial flap failure & $4(5.8)$ & $0(0.0)$ & 0.045 \\
\hline Late total flap failure & $6(8.7)$ & $0(0.0)$ & 0.014 \\
\hline Late evacuation of hematoma & $8(11.6)$ & $0(0.0)$ & 0.004 \\
\hline
\end{tabular}




\begin{tabular}{|l|l|l|l|}
\hline Late surgical site revision & $18(26.1)$ & $2(3.0)$ & $<0.001$ \\
\hline Late surgical site exploration & $0(0.0)$ & $1(1.5)$ & 0.31 \\
\hline Late new free flap & $10(14.5)$ & $0(0.0)$ & 0.001 \\
\hline Late new other flap & $7(10.1)$ & $0(0.0)$ & 0.007 \\
\hline Late pneumonia & $15(21.7)$ & $7(10.4)$ & 0.074 \\
\hline Late sepsis & $6(8.7)$ & $2(3.0)$ & 0.16 \\
\hline Late pulmonary edema & $7(10.1)$ & $5(7.5)$ & 0.58 \\
\hline Late myocardial infarction & $2(2.9)$ & $1(1.5)$ & 0.58 \\
\hline
\end{tabular}

SOFA: Sequential Organ Failure Assessment; APACHEII: Acute Physiology and Chronic Health Evaluation; Hosp LOS: hospital length of stay; ICU LOS: intensive care unit length of stay.

Table 4

Characteristics of the $\mathbf{1 3 6}$ patients who underwent free flap surgery for cancer of the head and neck according to their one-year survival status

\begin{tabular}{|c|c|c|c|}
\hline & $\begin{array}{l}\text { Alive one year after } \\
\text { surgery } \\
n=109\end{array}$ & $\begin{array}{l}\text { Not alive one year } \\
\text { after surgery } \\
n=27\end{array}$ & p-value \\
\hline Age $<65$ y & $51(46.8)$ & $13(48.1)$ & \multirow{3}{*}{0.56} \\
\hline $65-75$ y & 38 (34.9) & $7(25.9)$ & \\
\hline$>75 y$ & $20(18.3)$ & $7(25.9)$ & \\
\hline $\begin{array}{l}\text { Tumor staging } \\
\text { T-score T1 }\end{array}$ & $\begin{array}{l}n=102 \\
4(3.7)\end{array}$ & $\begin{array}{l}n=25 \\
1(3.7)\end{array}$ & \multirow{4}{*}{0.28} \\
\hline $\mathrm{T} 2$ & $27(24.8)$ & $4(14.8)$ & \\
\hline T3 & $19(17.4)$ & $9(33.3)$ & \\
\hline $\mathrm{T4}$ & $52(47.7)$ & $11(40.7)$ & \\
\hline $\mathrm{N}$-score NO & $64(58.7)$ & $16(59.3)$ & \multirow{4}{*}{0.034} \\
\hline N1 & $16(14.7)$ & $3(11.1)$ & \\
\hline $\mathrm{N} 2$ & $22(20.2)$ & $4(14.8)$ & \\
\hline N3 & $0(0.0)$ & $2(7.4)$ & \\
\hline Early complications & $57(52.3)$ & $12(44.4)$ & 0.47 \\
\hline Late complications & $44(40.4)$ & $14(51.9)$ & 0.28 \\
\hline Surgical complications & $54(39.7)$ & $10(37.0)$ & 0.24 \\
\hline Medical complications & $36(33.3)$ & $15(55.6)$ & 0.030 \\
\hline Reoperation & $43(39.4)$ & $10(37.0)$ & 0.82 \\
\hline Readmission to ICU & $4(3.7)$ & $4(14.8)$ & 0.028 \\
\hline Fibular flap & $22(20.2)$ & $4(14.8)$ & 0.53 \\
\hline Alcohol abuse & $19(17.4)$ & $4(14.8)$ & 0.32 \\
\hline
\end{tabular}


Fig.1. Kaplan-Meier survival curves for the $\mathbf{1 3 6}$ patients who underwent free flap surgery for cancer of the head and neck who had late complications and who had no late complications

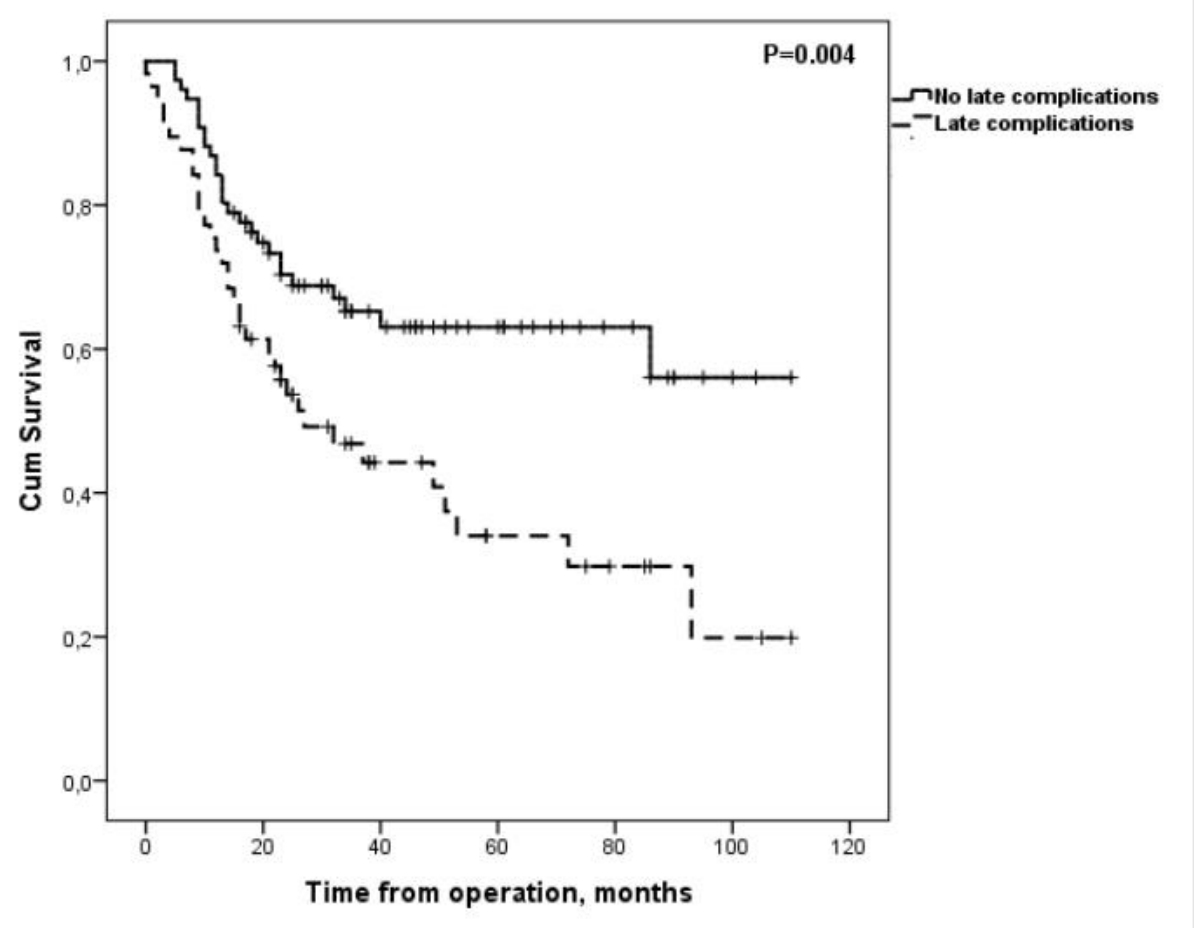

